\title{
Polyvinyl Pyrrolidone-Assisted Synthesis of Crystalline Manganese Vanadate Microtubes
}

\author{
Li-Zhai Pei*, Yin-Qiang Pei, Yi-Kang Xie, Chang-Zhou Yuan, Dian-Kai Li, Qian-Feng Zhang \\ Key Laboratory of Materials Science and Processing of Anhui Province, \\ Institute of Molecular Engineering and Applied Chemistry, \\ School of Materials Science and Engineering, Anhui University of Technology, \\ Ma'anshan, Anhui 243002, P. R. China
}

Received: June 6, 2012; Revised: September 2, 2012

\begin{abstract}
Manganese vanadate microtubes have been synthesized by a facile polyvinyl pyrrolidone-assisted hydrothermal route. $\mathrm{X}$-ray diffraction pattern confirms that the microtubes are composed of monoclinic $\mathrm{MnV}_{2} \mathrm{O}_{6}$, tetragonal $\mathrm{V}_{2} \mathrm{O}_{5}$ and orthorhombic $\mathrm{MnO}_{2}$ phases. The outer diameter and inner diameter of the microtubes are about $300 \mathrm{~nm}-3 \mu \mathrm{m}$ and $200 \mathrm{~nm}-1 \mu \mathrm{m}$, respectively. The tube wall thickness of the microtubes is about $50 \mathrm{~nm}-1 \mu \mathrm{m}$. The possible formation process of the manganese vanadate microtubes has been proposed as a polyvinyl pyrrolidone-assisted growth mechanism.
\end{abstract}

Keywords: manganese vanadate microtubes, crystal growth, photoluminescence, electron microscopy

\section{Introduction}

Recently, great research interest has been devoted to functional materials with solid rod-shaped structures and hollow tubular structures owing to their distinctive physical, chemical properties and potential application in the nanoscale devices ${ }^{1,2}$. Efforts have also been made to synthesize rod-shaped and tubular vanadate structures because of their potential applications in the fields of lithium batteries, sensors and photocatalysis ${ }^{3}$. Different rod-shaped and tubular vanadate structures, such as $\mathrm{LiV}_{3} \mathrm{O}_{8}$ nanorods ${ }^{4}$, silver vanadate nanorods ${ }^{5,6}$, cerium vanadate nanorod arrays ${ }^{7}, \mathrm{FeVO}_{4}$ nanorods ${ }^{8}$ and bismuth vanadate nanotubes ${ }^{9}$ have been synthesized by hydrothermal route, nanoporous anodic aluminum oxide template via sol-gel method and wet chemical process.

Manganese (Mn) vanadate, as a kind of important transition metal vanadate, has been researched extensively for lithium ion rechargeable batteries ${ }^{10,11}$. Mn vanadate powders have been prepared by solid state reaction process ${ }^{12}$, solution method ${ }^{13,14}$. Tubular Mn vanadate instead of bulk Mn vanadate may show novel physical and chemical properties due to special tubular structure for efficient electron transport and confinement effect. Therefore, it is important to synthesize crystalline tubular $\mathrm{Mn}$ vanadate by a facile route for the research of novel physical and chemical properties.

Functional materials with special morphologies, such as alumina nanotubes ${ }^{15}, \mathrm{AlOOH}$ nanotubes ${ }^{16}, \mathrm{ZnO}$ nanowires/nanorods ${ }^{17,18}$ and copper nanowires ${ }^{19}$ have been synthesized by a facile hydrothermal route using different surfactants. Surfactants can be used as versatile soft templates for the formation of functional materials with different morphologies. Polyvinyl pyrrolidone (PVP) is a kind of important surfactant which can assist the growth

*e-mail: lzpei@ahut.edu.cn of functional materials with different morphologies ${ }^{20-22}$. In the paper, crystalline Mn vanadate microtubes have been successfully synthesized via a facile PVP-assisted hydrothermal route using sodium orthovanadate $\left(\mathrm{Na}_{3} \mathrm{VO}_{4}\right)$ and $\mathrm{Mn}$ acetate $\left(\mathrm{Mn}\left(\mathrm{CH}_{3} \mathrm{COO}\right)_{2} \cdot 4 \mathrm{H}_{2} \mathrm{O}\right)$ as the raw materials, $\mathrm{PVP}$ as the surfactant. The possible growth process of the $\mathrm{Mn}$ vanadate microtubes has been discussed.

\section{Experimental}

$\mathrm{Na}_{3} \mathrm{VO}_{4}$ (AR grade, purity: $\geq 99.9 \%$ ) and PVP (AR grade) were purchased from Aladdin Reagent Co., Ltd. of China. $\mathrm{Mn}\left(\mathrm{CH}_{3} \mathrm{COO}\right)_{2} \cdot 4 \mathrm{H}_{2} \mathrm{O}$ (AR grade, purity: $\geq 99.0 \%$ ) was purchased from Sinopharm Chemical Reagent Co., Ltd. of China. In a typical procedure, $\mathrm{Na}_{3} \mathrm{VO}_{4}$, $\mathrm{Mn}\left(\mathrm{CH}_{3} \mathrm{COO}\right)_{2} \cdot 4 \mathrm{H}_{2} \mathrm{O}$ and PVP were dissolved in $60 \mathrm{~mL}$ distilled water. Then, the mixture was placed into a $100 \mathrm{~mL}$ autoclave with a Teflon liner. The autoclave was maintained at $180{ }^{\circ} \mathrm{C}$ for 24 hours. Subsequently the autoclave was cooled naturally in air. The resulting black precipitates were filtered, washed with distilled water for several times and dried at $60{ }^{\circ} \mathrm{C}$ in air. Finally, the black Mn vanadate powders were gained.

The synthesized products were characterized by X-ray diffraction (XRD), scanning electron microscopy (SEM), transmission electron microscopy (TEM), high-resolution transmission electron microscopy (HRTEM), infrared spectroscopy (IR) and photoluminescence (PL) spectrum. XRD pattern was carried out on a Bruker AXS D8 X-ray diffractometer with $\mathrm{Cu}-\mathrm{K} \alpha$ radiation $(\lambda=1.5406 \AA)$. The products were scanned at a scanning rate of $0.05 \%$ in the $2 \theta$ range of $10^{\circ} \sim 80^{\circ}$. SEM observation was performed using nova nanoSEM FEI 430 SEM. TEM and HRTEM observations were performed using JEOL JEM-2100 TEM with a GATAN digital photography system. IR spectroscopy 
(Perkin Elmer PE, WQF-410 spectrometer) was used at room temperature in the range of $400-4000 \mathrm{~cm}^{-1}$. PL measurement was carried out at room temperature using $212 \mathrm{~nm}$ as the excitation wavelength with a luminescence spectrometer (Cary Eclipse) in the range of 350-600 nm.

\section{Results and Discussion}

Figure 1a displays the SEM image of the Mn vanadate products grown from $180{ }^{\circ} \mathrm{C}$ for 24 hours using PVP as the surfactant. It is observed that the Mn vanadate products are composed of a large quantity of tubular structures with the length of about several dozens of micrometers. Some microtubes can be seen obviously which is designated by white arrows. No other structures are observed besides the tubular structures. The outer diameter and inner diameter of the $\mathrm{Mn}$ vanadate microtubes are about $300 \mathrm{~nm}$ to $3 \mu \mathrm{m}$ and $200 \mathrm{~nm}$ to $1 \mu \mathrm{m}$, respectively. The tube wall thickness of the microtubes is about $50 \mathrm{~nm}$ to $1 \mu \mathrm{m}$. The cracked microtube also shows the curved structure (designated by black arrow). The morphology of the Mn vanadate microtubes is similar to that of $\mathrm{ZnO}$ microtubes ${ }^{23-25}$ and $\mathrm{BiVO}_{4}$ microtubes ${ }^{26}$. The results indicate that the PVP-assisted hydrothermal route is an effective method for preparing Mn vanadate microtubes. To analyze the role of the PVP on the formation of Mn vanadate microtubes, the experiment under same synthesis conditions without PVP was performed. The SEM image of the products is shown in Figure 1b. It is interesting that only irregular particles with the sub-microscale size are obtained. The irregular particles are very different from those obtained from the same hydrothermal conditions using PVP as the surfactant. Generally, rod-like Mn vanadate containing crystal water can easily obtained by hydrothermal method. For example, Inagaki et al. ${ }^{27}$ and Morishita et al. ${ }^{12}$ reported the synthesis of rod-shaped $\mathrm{MnV}_{2} \mathrm{O}_{6}$ using $\mathrm{Mn}\left(\mathrm{CH}_{3} \mathrm{COO}\right)_{2}$ and $\mathrm{V}_{2} \mathrm{O}_{5}$ with a metal ion concentration of $0.01-1.0$ mol. $\mathrm{L}^{-1}$ at $135-200{ }^{\circ} \mathrm{C}$ under hydrothermal conditions. However, only irregular Mn vanadate particles are obtained without

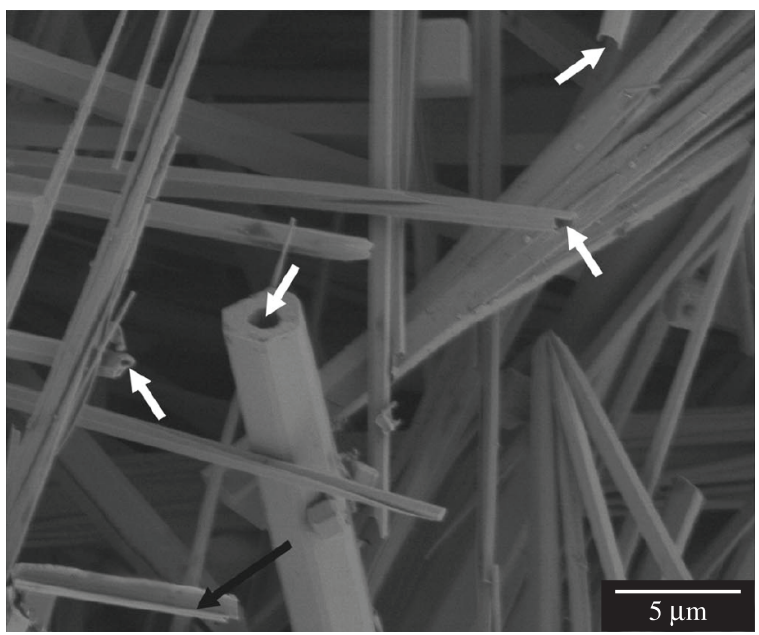

(a)
PVP. In our experiment, $\mathrm{Na}_{3} \mathrm{VO}_{4}$ is used as the $\mathrm{V}$ raw material instead of $\mathrm{V}_{2} \mathrm{O}_{5}$ and PVP is used as the surfactant. PVP and $\mathrm{Na}_{3} \mathrm{VO}_{4}$ are considered to have the essential roles on the formation of the Mn vanadate microtubes under present hydrothermal conditions.

The composition of the microtubes has been analyzed using energy dispersive spectrometer (EDS) equipped in the FESEM. Figure $2 b$ is the EDS spectrum of the microtubes corresponding to the white square in Figure 2a. It is clear that the $\mathrm{Mn}$ vanadate microtubes are composed of $\mathrm{Mn}, \mathrm{V}$ and $\mathrm{O}$.

The phase of the Mn vanadate microtubes is identified by XRD which is shown in Figure 3a. Most diffraction peaks can be indexed to monoclinic $\mathrm{MnV}_{2} \mathrm{O}_{6}$ phase (JCPDS card, No. 40-0165). Some diffraction peaks of tetragonal $\mathrm{V}_{2} \mathrm{O}_{5}$ (JCPDS card, No. 45-1074) and orthorhombic $\mathrm{MnO}_{2}$ phase (JCPDS card, No. 39-0375) are also indexed besides monoclinic $\mathrm{MnV}_{2} \mathrm{O}_{6}$ phase. The $\mathrm{V}_{2} \mathrm{O}_{5}$ and $\mathrm{MnO}_{2}$ phases may originate from the residue decomposed from $\mathrm{Na}_{3} \mathrm{VO}_{4}$ and $\mathrm{Mn}\left(\mathrm{CH}_{3} \mathrm{COO}\right)_{2}$. The XRD result shows that the $\mathrm{Mn}$ vanadate microtubes are composed of monoclinic $\mathrm{MnV}_{2} \mathrm{O}_{6}$, tetragonal $\mathrm{V}_{2} \mathrm{O}_{5}$ and orthorhombic $\mathrm{MnO}_{2}$ phases. The XRD pattern of the irregular particles obtained without PVP (Figure $3 \mathrm{~b}$ ) shows that the irregular particles are composed of orthorhombic $\mathrm{MnV}_{2} \mathrm{O}_{5}$ phase (JCPDS card, No. 51-0203). The phase is totally different from that obtained using PVP as the surfactant. The result shows that the PVP induces the phase transformation of the products from irregular particles to microtubes.

More structure formation of the Mn vanadate microtubes can be provided by TEM observations. Figure 4 is the TEM and HRTEM images of the Mn vanadate microtubes. From the general TEM image of the Mn vanadate microtubes (Figure 4a), the Mn vanadate microtubes with smooth surface exhibit the diameter of less than $3 \mu \mathrm{m}$ and length of several dozens of micrometers. The morphology and size of the Mn vanadate microtubes are similar to those observed by SEM observation. Obviously, TEM image at the tip of the Mn vanadate microtube is shown in Figure 4b, c exhibiting

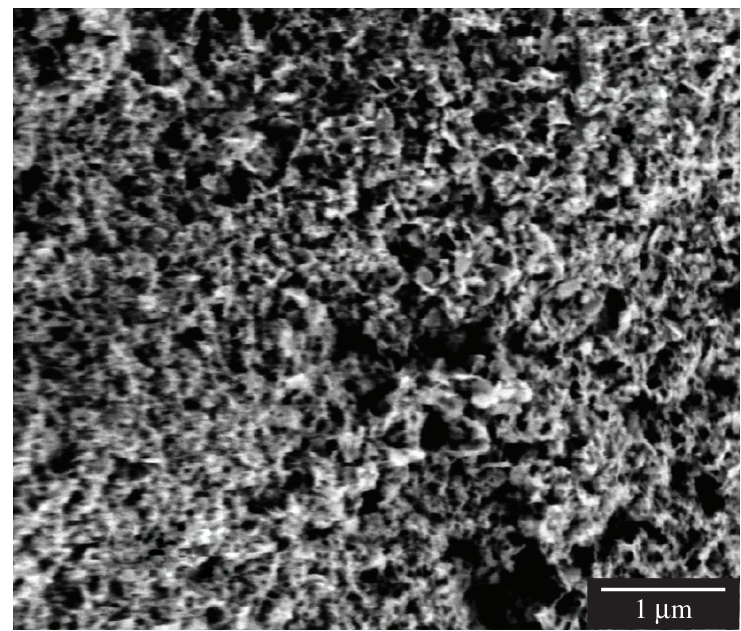

(b)

Figure 1. (a) SEM image of the Mn vanadate microtubes obtained from $180^{\circ} \mathrm{C}$ for 24 hours using PVP as the surfactant, (b) SEM image of the samples obtained from $180{ }^{\circ} \mathrm{C}$ for 24 hours without PVP. 
the tubular structure. The inner diameter and outer diameter are about $300 \mathrm{~nm}$ and $500 \mathrm{~nm}$, respectively. The tube wall thickness of the microtube is about $50 \mathrm{~nm}$. HRTEM analysis on the Mn vanadate microtubes may provide more structural information which may help to analyze the crystalline structure. However, the thickness of the Mn vanadate microtubes prevents the HRTEM observation. So only HRTEM image of the microtubes at the tip is measured which is shown in Figure 4d. The HRTEM image obviously shows that the microtubes have good crystalline structure.

The IR spectrum at $400-4000 \mathrm{~cm}^{-1}$ of the $\mathrm{Mn}$ vanadate microtubes obtained from $180{ }^{\circ} \mathrm{C}$ for 24 hours is shown in Figure 5. The broad absorption bands at 2800-3800 $\mathrm{cm}^{-1}$ with the absorption peaks of 3494 and $3423 \mathrm{~cm}^{-1}$ are the characteristic stretching vibration of $-\mathrm{OH}$ originated from water. The absorption peaks at 1647,1463 and $1294 \mathrm{~cm}^{-1}$

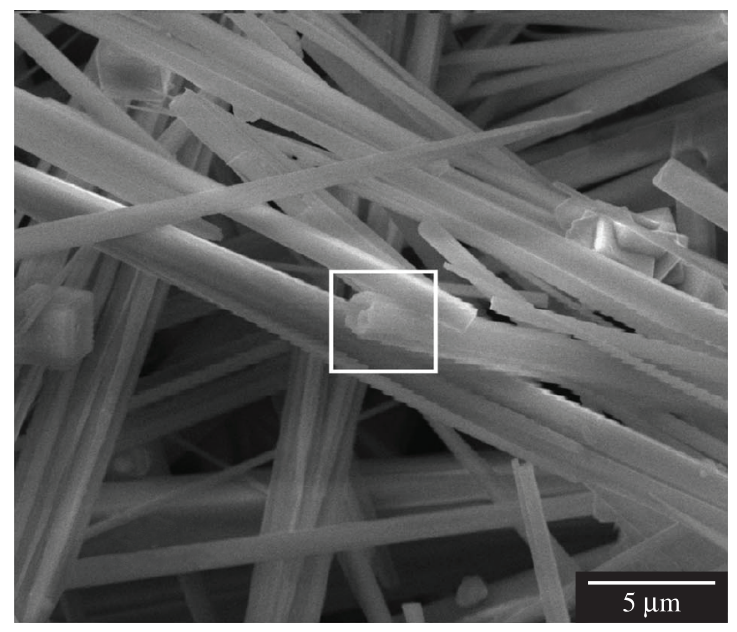

(a)

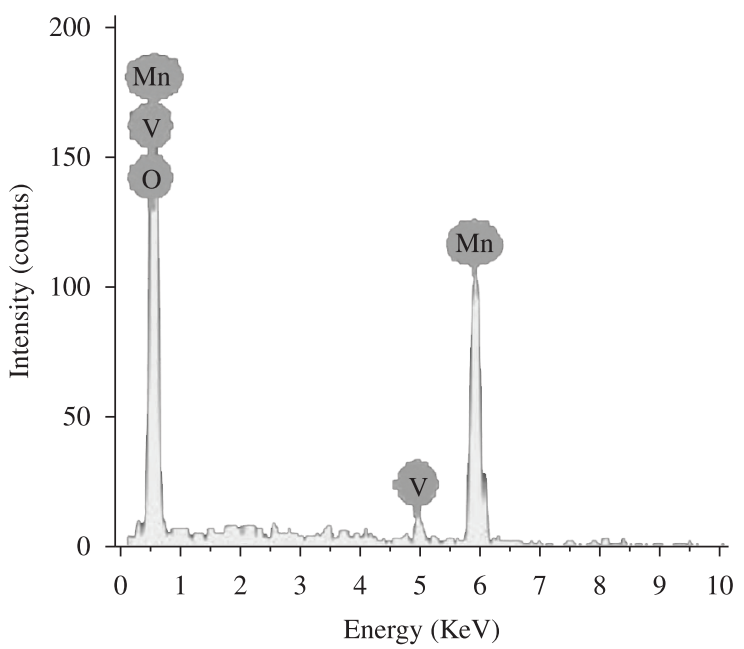

(b)

Figure 2. (a) SEM image of the Mn vanadate microtubes, (b) EDS spectrum of the microtubes corresponding to the white square in Figure 2a.

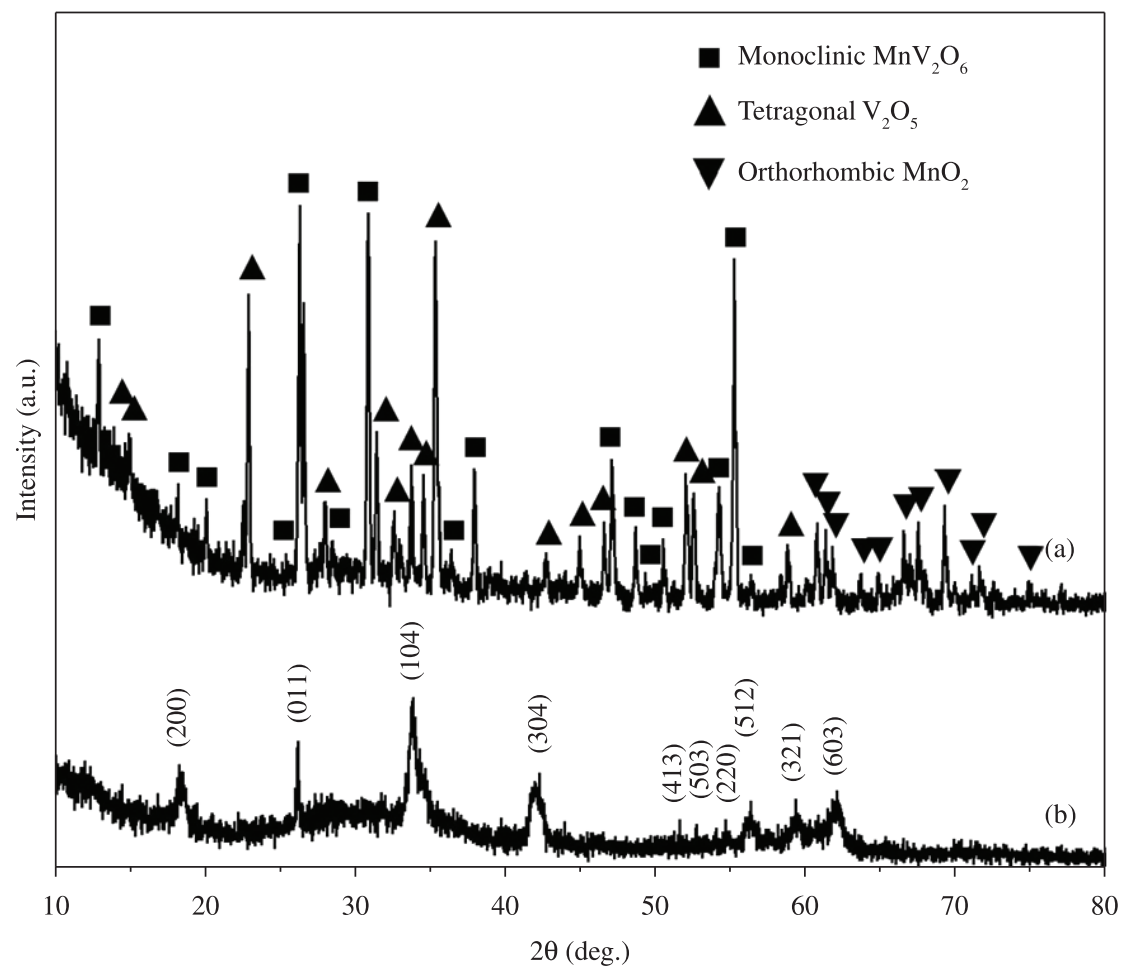

Figure 3. (a) XRD pattern of the Mn vanadate microtubes obtained from $180^{\circ} \mathrm{C}$ for 24 hours using PVP as the surfactant, (b) XRD pattern of the samples obtained from $180{ }^{\circ} \mathrm{C}$ for 24 hours without PVP. 
are assigned to the $\mathrm{C}=\mathrm{O}$ stretching, $\mathrm{CH}_{2}$ bending and $\mathrm{C}-\mathrm{N}$ stretching vibration, respectively in the $\mathrm{PVP}^{28}$. The absorption peak at $713 \mathrm{~cm}^{-1}$ contributes to the $\mathrm{Mn}-\mathrm{O}$ vibration of the products ${ }^{29}$. Yamaguchi et al. ${ }^{30}$ reported that $\mathrm{YVO}_{4}$ synthesized by the sol-gel procedure showed vibrations of $\mathrm{V}-\mathrm{O}$ bonding at 870,820 and $430 \mathrm{~cm}^{-1}$. IR spectrum of $\mathrm{LaVO}_{4}$ also exhibited the vibration of $\mathrm{V}-\mathrm{O}$ bonding at $432 \mathrm{~cm}^{-1}$ reported by Manca and Baran ${ }^{31}$. The absorption peaks located at 883,812 and $426 \mathrm{~cm}^{-1}$ are very close to those reported by above literatures. Therefore, these absorption peaks at 883,812 and $426 \mathrm{~cm}^{-1}$ are assigned to the vibration of $\mathrm{V}-\mathrm{O}$ bonding.

The room temperature PL spectrum of the Mn vanadate microtubes (Figure 6) shows violet and blue light emission centered at $425 \mathrm{~nm}$ and $492 \mathrm{~nm}$, respectively. A broad band emission from 400 to $700 \mathrm{~nm}$ was observed from $\mathrm{PL}$ spectrum of metavanadates $\mathrm{AVO}_{3}(\mathrm{~A}=\mathrm{K}, \mathrm{Rb} \text { and } \mathrm{Cs})^{32}$. Broad band emission spectrum between 400 and $800 \mathrm{~nm}$ from the $\mathrm{M}_{2} \mathrm{~V}_{2} \mathrm{O}_{7}(\mathrm{M}=\mathrm{Ca}, \mathrm{Sr}$ and $\mathrm{Ba})$ was also reported by Nakajima et al. ${ }^{33}$ The origin of the luminescence of $\mathrm{M}_{2} \mathrm{~V}_{2} \mathrm{O}_{7}$ phosphors may be the charge transfer transition from the oxygen $2 \mathrm{p}$ to vanadium $3 \mathrm{~d}$ orbitals in the $\mathrm{VO}_{4}$ tetrahedra ${ }^{34}$. The violet and blue light emission centered at $425 \mathrm{~nm}$ and $492 \mathrm{~nm}$ of the $\mathrm{Mn}$ vanadate microtubes are very similar to those of the above literatures. The Mn vanadate microtubes are mainly composed of monoclinic $\mathrm{MnV}_{2} \mathrm{O}_{6}$ and $\mathrm{V}_{2} \mathrm{O}_{5}$ phases besides $\mathrm{MnO}_{2}$ phase. Therefore, the PL spectrum of the Mn vanadate microtubes is

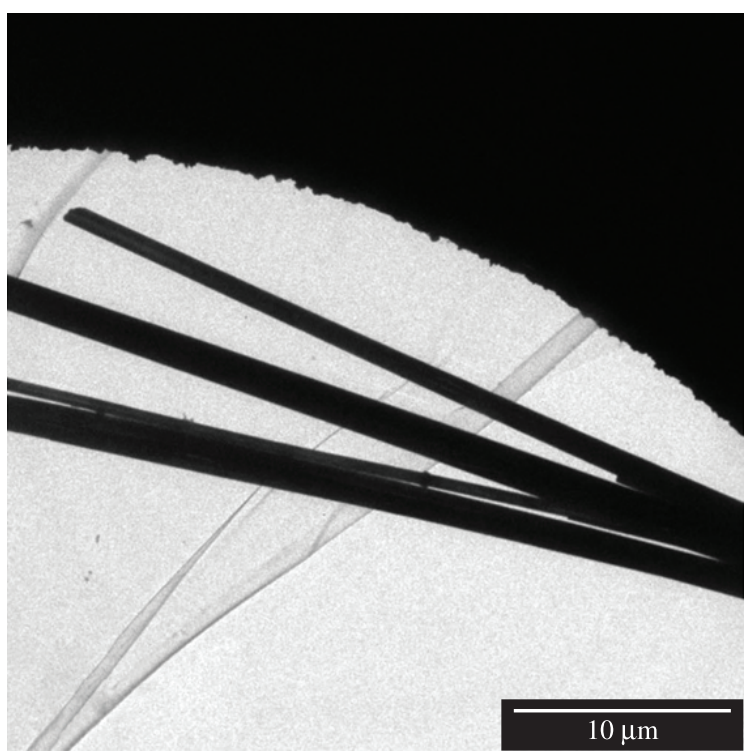

(a)

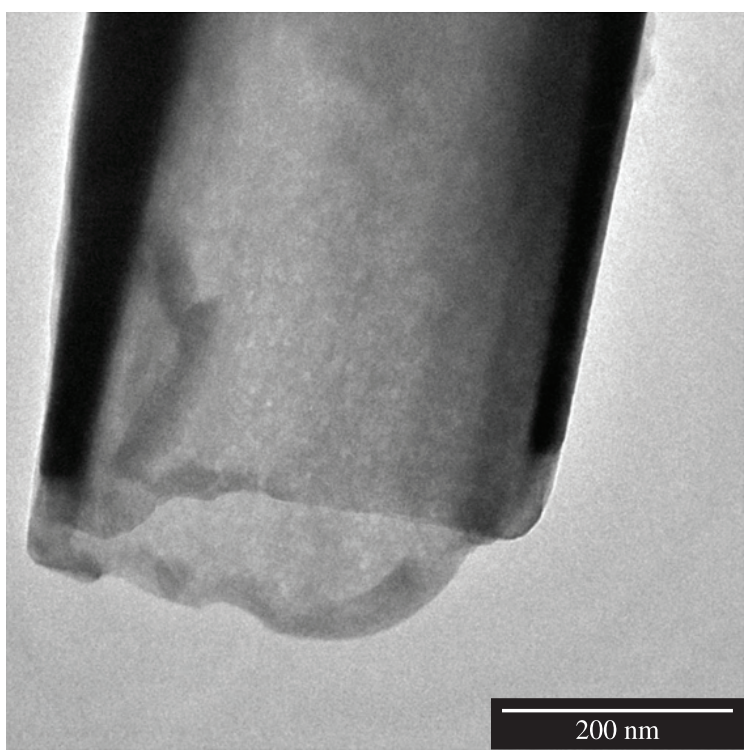

(c)

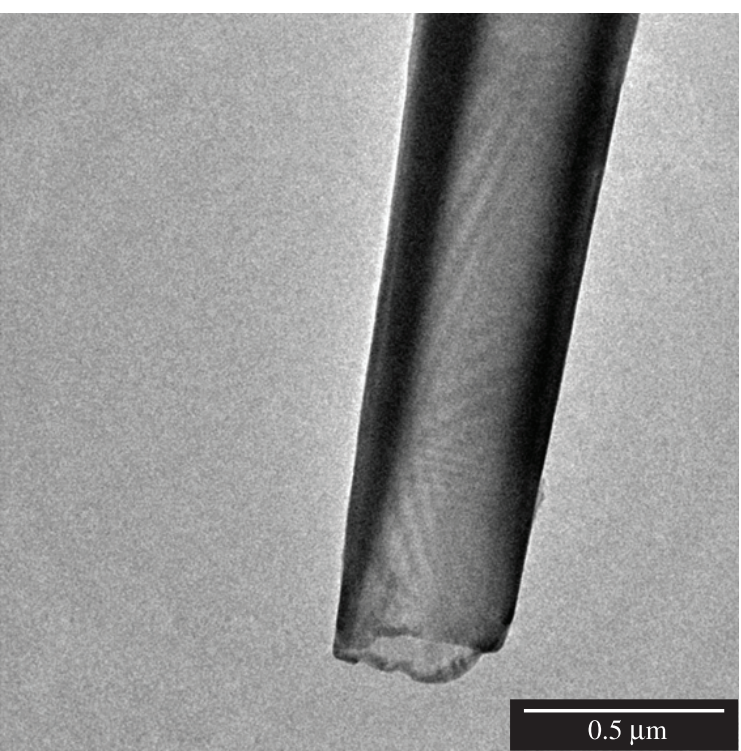

(b)

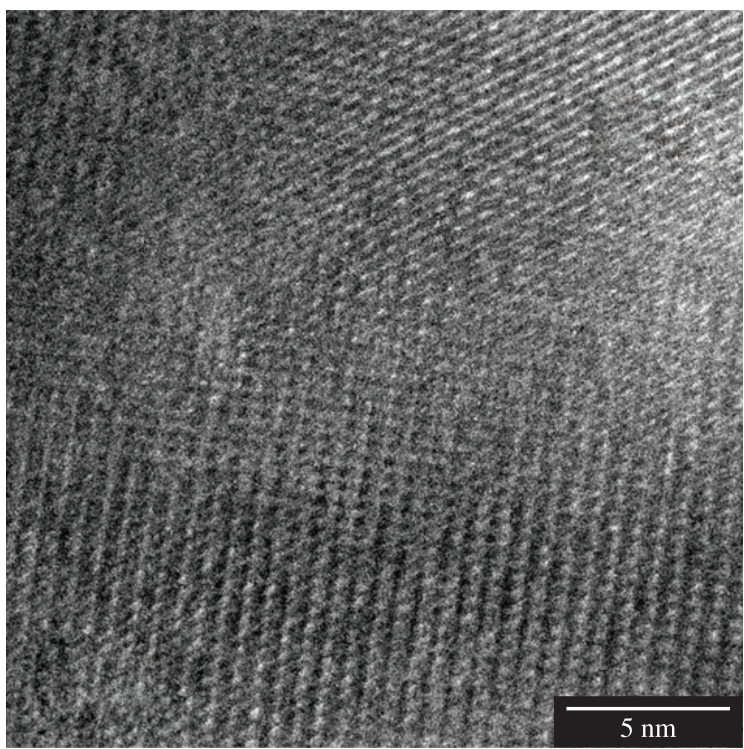

(d)

Figure 4. (a) General TEM image of the Mn vanadate microtubes, (b) and (c) TEM image of single Mn vanadate microtube with different magnifications showing the typical tubular structure, (d) HRTEM image of the Mn vanadate microtube. 


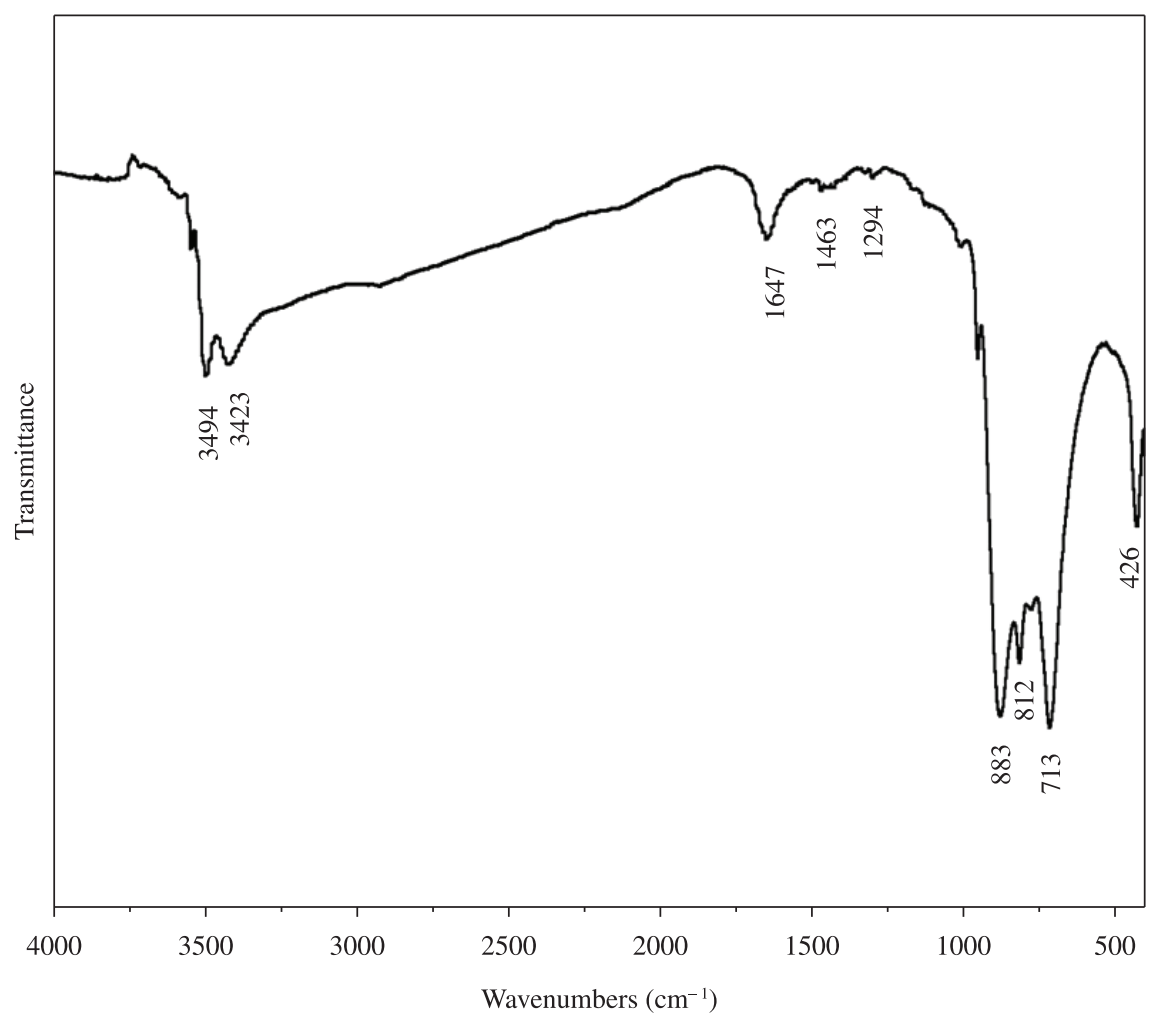

Figure 5. IR spectrum of the Mn vanadate microtubes.

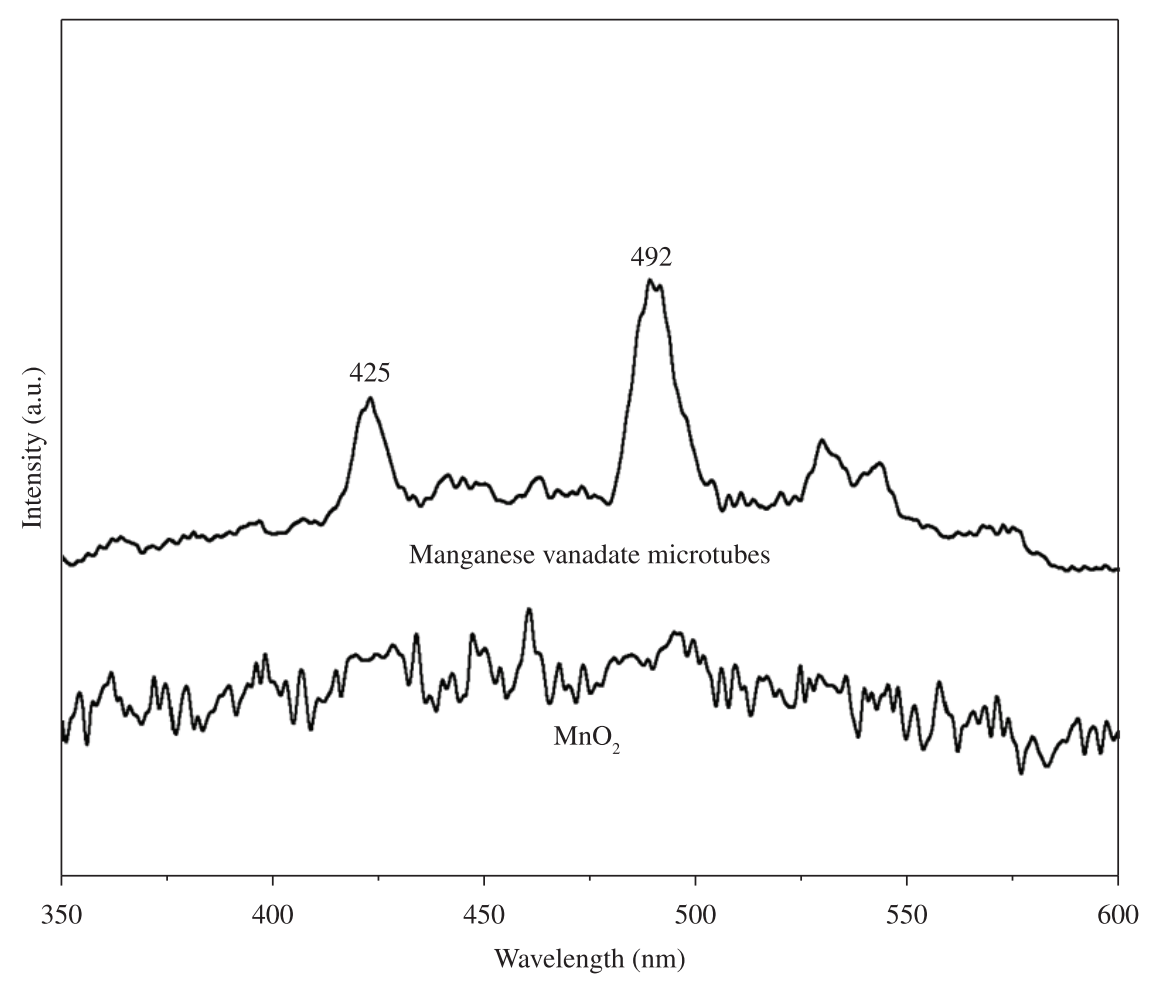

Figure 6. PL spectrum of the $\mathrm{Mn}$ vanadate microtubes and $\mathrm{MnO}_{2}$. 
considered to be originated from $\mathrm{V}-\mathrm{O}$ bonding. The emission centered at $425 \mathrm{~nm}$ is also considered to be the overtones of the excitation wave, which is similar to that reported by McGinley et al. ${ }^{35}$ However, the PL spectrum is very noisy. The samples present $\mathrm{OH}$ groups in the structure of material. This may be principal effect that luminescence is being suppressed. In addition, No PL peaks are observed from $\mathrm{MnO}_{2}$. So $\mathrm{MnO}_{2}$ in the $\mathrm{Mn}$ vanadate microtubes is also considered to contribute to the suppression of the luminescence.

The analysis on the formation mechanism of $\mathrm{Mn}$ vanadate microtubes is very important to understand the synthetic methods for the formation of tubular structure. Several models, such as curving followed by seaming of molecular layers ${ }^{36}$, helical nanobelt-twist-join-growth process $^{37}$ and rolling mechanism for the conversion from nanosheets to nanotubes ${ }^{38}$ have been proposed which can not explain the formation process of the Mn vanadate microtubes. Recently, Mo et al. ${ }^{39}$ reported the synthesis of $\beta-\mathrm{Mn}_{2} \mathrm{~V}_{2} \mathrm{O}_{7}$ microtubes with a length of $15-25 \mu \mathrm{m}$, 2.5-3.5 $\mu \mathrm{m}$ external diameter and $0.4 \mu \mathrm{m}$ wall thickness, as well as $\beta-\mathrm{Mn}_{2} \mathrm{~V}_{2} \mathrm{O}_{7}$ hollow microspheres in a suitable molar ratio of $\mathrm{NH}_{3} \mathrm{VO}_{3}$ and $\mathrm{MnCO}_{3}$ powders via a hydrothermal process without surfactants. They contribute to the tubular morphology caused by layered oxide structure. However, different from the raw materials of $\mathrm{NH}_{3} \mathrm{VO}_{3}$ and $\mathrm{MnCO}_{3}$ reported by Liu et al. ${ }^{37}, \mathrm{Na}_{3} \mathrm{VO}_{4}, \mathrm{Mn}\left(\mathrm{CH}_{3} \mathrm{COO}\right)_{2}$ and PVP are used as the raw materials in our experiments. Therefore, the formation of the Mn vanadate microtubes may take a different formation process. In fact, crystalline $\mathrm{MnV}_{2} \mathrm{O}_{6}$ powders with irregular particles and rod-like particles have been synthesized via a hydrothermal process using $\mathrm{Mn}\left(\mathrm{CH}_{3} \mathrm{COO}\right)_{2}$ and $\mathrm{V}_{2} \mathrm{O}_{5}$ as the raw materials without surfactants ${ }^{27,40}$. It is well known that surfactant-assisted reaction to control the nucleation and growth is a simple and effective method. The surfactant molecules can modulate the kinetics of the crystal growth and determine the subsequent morphology of the product ${ }^{20,41-43}$.

In recent years, some research groups ${ }^{44-46}$ reported that the surfactants could alter the surface energy of various crystallographic surfaces to promote selective anisotropic growth of crystals. Only Mn vanadate microtubes can be

\section{References}

1. Shao MW, Qian GX, Ban HZ, Li M, Hu H, Lu L et al. Synthesis and magnetic property of quasi one-dimensional $\mathrm{Ni}$ nanostructures via $\mathrm{Si}$ nanowire template. Scripta Materialia. 2006; 55:851-854. http://dx.doi.org/10.1016/j. scriptamat.2006.08.003

2. Qian JM, Wang JP, Hou GY, Qiao GJ and Jin ZH. Preparation and characterization of biomorphic SiC hollow fibers from wood by chemical vapor infiltration. Scripta Materialia. 2005; 53:1363-1368. http://dx.doi.org/10.1016/j. scriptamat.2005.08.029

3. Souza Filho AG, Ferreira OP, Santos EJG, Mendes Fiho J and Alves OL. Raman spectra in vanadate nanotubes revisited. Nano Letters. 2004; 4:2099-2104. http://dx.doi.org/10.1021/ n10488477 synthesized by adding PVP under hydrothermal conditions. Therefore, PVP is considered to be a structure-directing agent for the growth of the Mn vanadate microtubes. PVP is a long chain polymer with each pyrrolidone unit chemically bonded to a polyethylene main chain ${ }^{47}$ forming PVP micelles. The PVP micelles are filled with polyethylene chains and entrapped water which may have a good stability to solubilize nanoparticles. Under the hydrothermal conditions, $\mathrm{MnV}_{2} \mathrm{O}_{6}$ nanoparticles are generated and crystallize to form $\mathrm{MnV}_{2} \mathrm{O}_{6}$ nuclea. Hence $\mathrm{MnV}_{2} \mathrm{O}_{6}$ nanoparticles can exist either in water or in the PVP micelles. PVP which is used as a structure-directing agent plays a crucial role in controlling the distribution of $\mathrm{MnV}_{2} \mathrm{O}_{6}$ nanoparticles in the hydrothermal solution and leads to the formation of $\mathrm{Mn}$ vanadate microtubes following a polyol-assisted formation mechanism ${ }^{48,49}$. Only irregular particles are generated without PVP. However, a plenty of micelles and Mn vanadate nanoparticles are filled in the PVP micelles. PVP micelles alter the surface energies of the Mn vanadate surfaces to promote the selective anisotropic growth of crystals leading to the formation of Mn vanadate microtubes.

\section{Conclusions}

In summary, novel crystalline Mn vanadate microtubes have been synthesized via a facile hydrothermal route in the presence of PVP. The Mn vanadate microtubes with the length of about several dozens of micrometers are composed of monoclinic $\mathrm{MnV}_{2} \mathrm{O}_{6}$, tetragonal $\mathrm{V}_{2} \mathrm{O}_{5}$ and orthorhombic $\mathrm{MnO}_{2}$ phases. The outer diameter and inner diameter of the $\mathrm{Mn}$ vanadate microtubes are about $300 \mathrm{~nm}-3 \mu \mathrm{m}$ and $200 \mathrm{~nm}$ to $1 \mu \mathrm{m}$, respectively. The tube wall thickness of the microtubes is about $50 \mathrm{~nm}$ to $1 \mu \mathrm{m}$. PVP-assisted hydrothermal route is potentially extendable to other inorganic tubular materials.

\section{Acknowledgements}

This work was supported by the Natural Science Foundation of Anhui Province (1208085QE98), Innovative Research Foundation of Postgraduate of Anhui University of Technology (2011005) and National Natural Science Foundation of China (90922008).
4. Xu HY, Wang H, Song ZQ, Wang YW, Yan H and Yoshimura M. Novel chemical method for synthesis of $\mathrm{LiV}_{3} \mathrm{O}_{8}$ nanorods as cathode materials for lithium ion batteries. Electrochimica Acta. 2004; 49:349-353. http://dx.doi.org/10.1016/j. electacta.2003.08.017

5. Pan GT, Lai MH, Juang RC, Chung TW and Yang TCK. Preparation of visible-light-driven silver vanadates by a microwave-assisted hydrothermal method for the photodegradation of volatile organic vapors. Industrial and Engineering and Chemistry Research. 2011; 50:2807-2814. http://dx.doi.org/10.1021/ie1012932

6. Singh DP, Polychronopoulou K, RebholzC andAouadi SM. Room temperature synthesis and high temperature frictional study of silver vanadate nanorods. Nanotechnology. 2010; 21:325601. http://dx.doi.org/10.1088/0957-4484/21/32/325601 
7. Liu JF, Wang LL, Sun XM andZhu XQ. Cerium vanadate nanorod arrays from ionic chelator-mediated self-assembly. Angewandte Chemie International Edition. 2010; 49:3492-3495. http:// dx.doi.org/10.1002/anie.201000783

8. Ma H, Yang XJ, Tao ZL, Liang J and Chen J. Controllable synthesis and characterization of porous $\mathrm{FeVO}_{4}$ nanorods and nanoparticles. CrystEngComm. 2011; 13:897-901. http:// dx.doi.org/10.1039/c0ce00273a

9. Singh S, Kumari N, Varma KBR and Krupanidhi SB. Synthesis, structural characterization and formation mechanism of ferroelectric bismuth vanadate nanotubes. Journal of Nanoscience and Nanotechnology. 2009; 9:6549-6553. http:// dx.doi.org/10.1166/jnn.2009.1300

10. Andrukaitis E. Lithium intercalation into the copper, nickel or manganese vanadates $\mathrm{Me}\left(\mathrm{VO}_{3}\right)_{2} \cdot \mathrm{yH}_{2} \mathrm{O}$. Journal of Power Sources. 1997; 68:652-655. http://dx.doi.org/10.1016/ S0378-7753(96)02572-4

11. Andrukaitis E, Torlone GL and Hill IR. Study of $\mathrm{Me}_{\mathrm{x}}\left(\mathrm{VO}_{3}\right)_{2}$ vanadates, $(\mathrm{Me}=\mathrm{Co}, \mathrm{Ni}, \mathrm{Mn}, 1<\mathrm{x}<2)$ for lithium rechargeable cells. Journal of Power Sources. 1999; 81-82:651-655. http:// dx.doi.org/10.1016/S0378-7753(99)00094-4

12. Morishita T, Konno H, Izumi Y and Inagaki M. Oxidation state of vanadium in amorphous $\mathrm{MnV}_{2} \mathrm{O}_{6}$ formed during discharge-charge cycle and the improvement of its synthesis condition. Solid State Ionics. 2006; 177:1347-1353. http:// dx.doi.org/10.1016/j.ssi.2006.05.035

13. Leroux F, Piffard Y, Ourvard G, Mansot JL and Guyomard D. New amorphous mixed transition metal oxides and their $\mathrm{Li}$ derivatives: Synthesis, characterization, and electrochemical behavior. Chemistry of Materials. 1999; 11:2948-2959. http:// dx.doi.org/10.1021/cm991074g

14. Liao JH, Drezen T, Leroux F, Guyomard D and Piffard Y. Synthesis, structures and thermal analysis of $\mathrm{MnV}_{2} \mathrm{O}_{6 \times n} \mathrm{H}_{2} \mathrm{O}$ phases (n=1, 2 and 4). European Journal of Solid State Inorganic Chemistry. 1996; 33:411-427.

15. Qu LH, He CQ, Yang Y, He YL and Liu ZM. Hydrothermal synthesis of alumina nanotubes templated by anionic surfactant. Materials Letters. 2005; 59:4034-4037. http://dx.doi. org/10.1016/j.matlet.2005.07.059

16. Kuang DB, Fang YP, Liu HQ, Frommen $\mathrm{C}$ and Fenske D. Fabrication of boehumite $\mathrm{AlOOH}$ and $\gamma-\mathrm{Al}_{2} \mathrm{O}_{3}$ nanotubes via a soft solution route. Journal of Materials Chemistry. 2003; 13:660-662. http://dx.doi.org/10.1039/ b212885c

17. Sun GB, Cao MH, Wang YH, Hu CW, Liu YC, Ren L et al. Anionic surfactant-assistd hydrothermal synthesis of high-aspect-ratio $\mathrm{ZnO}$ nanowires and their photoluminescence property. Materials Letters. 2006; 60:2777-2782. http://dx.doi. org/10.1016/j.matlet.2006.01.088

18. Sun XM, Chen X, Deng ZX and Li YD. A CTAB-assisted hydrothermal orientation growth of $\mathrm{ZnO}$ nanorods. Materials Chemistry and Physics. 2002; 78:99-104. http://dx.doi. org/10.1016/S0254-0584(02)00310-3

19. Liu ZP, Yang Y, Liang JB, Hu ZK, Li S, Peng S et al. Synthesis of copper nanowires via a complex-surfactant-assisted hydrothermal reduction process. Journal of Physics and Chemistry B. 2003; 107:12658-12661. http://dx.doi. org/10.1021/jp036023s

20. Zheng DS, Sun SS, Fan WL, Yu HY, Fan CH, Cao GX et al. One-step preparation of single-crystalline $\beta-\mathrm{MnO}_{2}$ nanotubes. Journal of Physics and Chemistry B. 2005; 109:16439-16443. http://dx.doi.org/10.1021/jp0523701

21. Yin YD, Lu Y, Sun YG and Xia YN. Silver nanowires can be directly coated with amorphous silica to generate well-controlled coaxial nanocables of silver/silica. Nano Letters. 2002; 2:427-430. http://dx.doi.org/10.1021/n1025508+

22. Wang JW, Wang X, Peng Q and Li YD. Synthesis and characterization of bismuth single-crystalline nanowires and nanospheres. Inorganic Chemistry. 2004; 43:7552-7556. http:// dx.doi.org/10.1021/ic049129q

23. Zhang W, Zhang D, Fan TX, Ding J, Guo QX and Ogawa H. Fabrication of $\mathrm{ZnO}$ microtubes with adjustable nanopores on the walls by the templating of butterfly wing scales. Nanotechnology. 2006; 17:840-844. http://dx.doi. org/10.1088/0957-4484/17/3/038

24. Jeong JS, Lee JY, Cho JH, Suh HJ and Lee CJ. Single-crystalline $\mathrm{ZnO}$ microtubes formed by coalescence of $\mathrm{ZnO}$ nanowires using a simple metal-vapor deposition method. Chemistry of Materials. 2005; 17:2752-2756. http://dx.doi.org/10.1021/ cm0493871

25. Vayssiers L, Kels K, Hagfeldt A and Lindquist SE. Three-dimensional array of highly oriented crystalline $\mathrm{ZnO}$ microtubes. Chemistry of Materials. 2001; 13:4395-4398. http://dx.doi.org/10.1021/cm011160s

26. Zhou L, Wang WZ, Zhang LS, Xu HL and Zhu W. Single-crystalline $\mathrm{BiVO}_{4}$ microtubes with square cross-sections: Microstructure, growth mechanism, and photocatalytic property. Journal of Physics and Chemistry C. 2007; 111:13659-13664. http://dx.doi.org/10.1021/ jp065155t

27. Inagaki M, Morishita T, Hirano M, Gupta V and Nakajima T. Synthesis of $\mathrm{MnV}_{2} \mathrm{O}_{6}$ under autogenous hydrothermal conditions and its anodic performance. Solid State Ionics. 2003; 156:275-282. http://dx.doi.org/10.1016/ S0167-2738(02)00679-3

28. Zhang TR, Lu R, Liu XL, Zhao YY, Li TJ and Yao JN. Photochromic polyoxotungstoeuropate $\mathrm{K}_{12}\left[\operatorname{EuP}_{5} \mathrm{~W}_{30} \mathrm{O}_{110}\right] /$ polyvinylpyrrolidone nanocomposite films. Journal of Solid State Chemistry. 2003; 172:458-463. http://dx.doi.org/10.1016/ S0022-4596(03)00036-7

29. Wang HE, Lu ZG, Qian D, Li YJ and Zhang W. Single-crystal $\alpha-\mathrm{MnO}_{2}$ nanorods: synthesis and electrochemical properties. Nanotechnology. 2007; 18:115616. http://dx.doi. org/10.1088/0957-4484/18/11/115616

30. Yamaguchi O, Mukaida Y, Shigeta H, Takemura H and Yamashita M. Preparation of alkoxy-derived $\mathrm{YVO}_{4}$. Materials Letters. 1988; 7:158-160. http://dx.doi.org/10.1016/0167-57 7X(88)90176-0

31. Manca SG and Baran EJ. Characterization of the monoclinic form of praseodymium chromate (V). Journal of Physics and Chemistry of Solids. 1981; 42:923-925. http://dx.doi. org/10.1016/0022-3697(81)90018-4

32. Nakajima T, Isobe M, Tsuchiya T, Ueda $Y$ and Kumagai T. Direct fabrication of metavanadate phosphor films on organic substrates for white-light-emitting devices. Nature Materials. 2008; 7:735-740. http://dx.doi.org/10.1038/ nmat 2244

33. Nakajima T, Isobe M, Tsuchiya T, Ueda $\mathrm{Y}$ and Manabe T. Photoluminescence property of vanadates $\mathrm{M}_{2} \mathrm{~V}_{2} \mathrm{O}_{7}(\mathrm{M}: \mathrm{Ba}, \mathrm{Sr}$ and Ca). Optical Materials. 2010; 32:1618-1621. http://dx.doi. org/10.1016/j.optmat.2010.05.021

34. Park KC and Mho SI. Photoluminescence properties of $\mathrm{Ba}_{3} \mathrm{~V}_{2} \mathrm{O}_{8}, \mathrm{Ba}_{3(1-\mathrm{x})} \mathrm{Eu}_{2 \mathrm{x}} \mathrm{V}_{2} \mathrm{O}_{8}$ and $\mathrm{Ba}_{2} \mathrm{Y}_{2 / 3} \mathrm{~V}_{2} \mathrm{O}_{8}: \mathrm{Eu}^{3+}$. Journal of Luminescence. 2007; 95:122-123.

35. McGinley ES and Crim FF. Homogeneous and inhomogeneous structure in the vibrational overtone spectrum of tetramethyldloxetane. Journal of Chemistry 
and Physics. 1986; 85:5741-5747. http://dx.doi. org/10.1063/1.451535

36. Ye C, Meng G, Jiang Z, Wang Y, Wang G and Zhang L. Rational growth of $\mathrm{Bi}_{2} \mathrm{~S}_{3}$ nanotubes from quasi-two-dimensional precursors. Journal of the American Chemical Society. 2002; 124:15180-15181. http://dx.doi.org/10.1021/ ja0284512

37. Mo MS, Zeng JH, Liu XM, Yu WC, Zhang SY and Qian YT. Controlled hydrothermal synthesis of thin single-crystal tellurium nanobelts and nanotubes. Advanced Materials. 2002; 14:1658-1662. http://dx.doi.org/10.1002/152 1-4095(20021118)14:22<1658::AID-ADMA1658>3.0.CO;2-2

38. Wang $X$ and Li YD. Rational synthetic strategy. From layered structure to $\mathrm{MnO}_{2}$ nanotubes. Chemistry Letters. 2004; 33:48-49. http://dx.doi.org/10.1246/cl.2004.48

39. Liu Y and Qian YT. Controllable synthesis of $\beta-\mathrm{Mn}_{2} \mathrm{~V}_{2} \mathrm{O}_{7}$ microtubes and hollow microspheres. Frontiers of Chemistry in China. 2008; 3:467-470. http://dx.doi.org/10.1007/ s11458-008-0061-9

40. Kim SS, Ikuta $\mathrm{H}$ and Wakihar M. Synthesis and characterization of $\mathrm{MnV}_{2} \mathrm{O}_{6}$ as a high capacity anode material for a lithium secondary battery. Solid State Ionics. 2001; 139:57-65. http:// dx.doi.org/10.1016/S0167-2738(00)00816-X

41. Xia Y, Yang P, Sun Y, Wu Y, Mayers B, Gates B et al. One-dimensional nanostructures: Synthesis, characterization, and applications. Advanced Materials. 2003; 15:353-389. http://dx.doi.org/10.1002/adma.200390087

42. Sun Y, Yin Y, Mayers BT, Herricks T and Xia Y. Uniform silver nanowires synthesis by reducing $\mathrm{AgNO}_{3}$ with ethylene glycol in the presence of seeds and poly(vinyl pyrrolidone).
Chemistry of Materials. 2002; 14:4736-4745. http://dx.doi. org/10.1021/cm020587b

43. Peng X, Manna L, Yang WD, Wickham J, Scher E, Kadavanich A et al. Shape control of CdSe nanocrystals. Nature. 2000; 404:59-61. http://dx.doi.org/10.1038/35003535

44. Peng X. Mechanisms for the shape-control and shape-evolution of colloidal semiconductor nanocrystals. Advanced Materials. 2003; 15:459-463. http://dx.doi.org/10.1002/ adma.200390107

45. Lee SM, Cho SN and Cheon J. Anisotropic shape control of colloidal inorganic nanocrystals. Advanced Materials. 2003; 15:441-443. http://dx.doi.org/10.1002/ adma.200390102

46. Guo L, Liu C, Wang R, Xu H, Wu Z and Yang S. Large-scale synthesis of uniform nanotubes of a nickel complex by a solution chemical route. Journal of the American Chemical Society. 2004; 126:4530-4531. http://dx.doi.org/10.1021/ ja039381h

47. Li LJ, Nicholas RJ, Chen CY, Darton RC and Baker SC. Comparative study of photoluminescence of single-walled carbon nanotubes wrapped with sodium dodecyl sulfate, surfactin and polyvinylpyrrolidone. Nanotechnology. 2005; 16:S202-S205. http://dx.doi.org/10.1088/0957-4484/16/5/012

48. Mayers B and Xia Y. Formation of tellurium nanotubes through concentration depletion at the surfaces of seeds. Advanced Materials. 2002; 14:279-281. http://dx.doi.org/10.1002/152 1-4095(20020219)14:4<279::AID-ADMA279>3.0.CO;2-2

49. Ma YR, Qi LM, Ma JM and Cheng HM. Micelle-mediated synthesis of single-crystalline selenium nanotubes. Advanced Materials. 2004; 16:1023-1026. http://dx.doi.org/10.1002/ adma.200400071 